trên 599 bệnh nhân cho thây phân nhóm creatinin máu không ảnh hưởng đến độ chính xác của nồng độ NT-pro BNP huyết thanh trong chẩn đoán suy tim [7].

\section{KẾT LUẬN}

Giá trị trung bình nồng độ NT-pro BNP huyết thanh của bệnh nhân suy tim do tăng huyết áp ở nhóm giai đoạn A là 2168,92 $\pm 2884,87 \mathrm{pg} / \mathrm{ml}$, giai đoạn $B$ là $2826,20 \pm 1743,56 \mathrm{pg} / \mathrm{ml}$, giai đoạn C là 11137,83 $\pm 8058,43 \mathrm{pg} / \mathrm{ml}$ và giai đoạn D là $16213,51 \pm 10944,03 \mathrm{pg} / \mathrm{ml}(\mathrm{p}<0,05)$.

Nồng độ NT-pro BNP huyết thanh có mối tương quan thuận chặt chẽ với các giai đoạn của suy tim theo AHA/ACC-2008 $(r=0,63 ; p<0,05)$ và với phân độ suy tim theo NYHA $(r=0,53 ; p<0,05)$.

\section{TÀl LIÊU THAM KHẢO}

1. Vũ Hoàng Vũ (2008), "Giá trị của NT-pro BNP trong chẩn đoán suy tim", Đại học Y Dược Thành phố Hồ Chí Minh.

2. Austin W., Bhala V. (2015), "Correlation and prognostic utility of BNP and its amino-terminal fragment in patients with chronic kidney disease", American J Clin Pathol. 126: p. 506-512.
3. Abdulle, A.M., et al. (2007), "Plasma N terminal pro-brain natriuretic peptide levels and its determinants in a multi-ethnic population", J Hum Hypertens. 21: p. 647-653.

4. Bayés, A., G.M. Santaló, B.E. Zapico (2004), "Nterminal probrain natriuretic peptide in the emergency diagnosis and in-hospital monitoring of patients with dysapnea and ventricualar dysfuntion", European Journal of Heart Failure, p. 301-308.

5. Dickstein, K., A. Cohen-Solal, G. Filippatos (2008), "ESC guidelines for the diagnosis and treatment of acute and chronic heart failure 2008", Eur J Heart Fail. 10: p. 933-989.

6. Nielsen, O.W., et al. (2003), "Retrospective analysis of the cost-effectiveness of using plasma brain natriuretic peptide in screening for left ventricular systolic dysfunction in the general population", J Am Coll Cardiol. 41: p. 113-120.

7. Januzzi, J.L., et al. (2015), "The N-terminal NTpro BNP investigation of dyspnea in the emergency department (PRIDE) study", Am J Cardiol. 95: p. 948-954.

8. Zaphiriou A, R.S., Murray-Thomas T, Mendez G, (2005), "The diagnostic accuracy of plasma BNP and NTproBNP in patients referred from primary care with suspected heart failure: results of the UK natriuretic peptide study", Eur J Heart Fail. 7: p. 537-541.

\title{
MộT SỐ ĐẶC ĐIỂM HÌNH THÁI KHỚP CẮN HỞ NGƯờI VIỆT NAM TRÊN PHIM SỌ NGHIÊNG TELE TỪ XA (CEPHALOMETRICS)
}

\author{
Đỗ Thị Bình ${ }^{1}$, Nguyễn Thị Bích Ngọc ${ }^{1}$, Nguyễn Thanh Huyền ${ }^{2}$
}

\section{TÓM TẮT}

Khớp cắn hở phía trước là tình trang sai khớp cắn ảnh hưởng nhiều đến hoạt động chức năng và thẩm mỹ. Đồng thời, sự ổn định sau điều trị của loại sai khớp cắn này luôn là thách thức cho bác sĩ chỉnh nha. Nghiên cứu nhằm mục đích mô tả một số đăc điểm hình thái 36 bệnh nhẩn người Việt Nam, độ tuổi từ 1018 tuổi, có khớp cắn hở phía trước trền phim so nghiêng tele từ xa Cephalometric đến khám tại Bệnh viện Răng Hàm Mặt Trung Ương và Viện Đào tạo Rẳng Hàm Mặt. Kết quả nghiên cứu cho thấy khớp cẳn hở là loại hình sai khớp cắn ít gặp, xuất hiện nhiều ở nữ hởn, tuy nhiên không có sự khác biệt có ý nghĩa thống kê giữa hai giới. Phần lớn cắn hở ở mức độ trung bình $(-1,39 \pm 0,499 \mathrm{~mm})$. Chiếm tỉ lệ nhiều nhất là sai khớp cắn hạng III xương $(n=15 ; 41,7 \%)$, Chiều cao tâng mặt dưới (LAFH) trung bình là $63,41 \pm 6,185 \mathrm{~mm}$ (nữ) và $68,29 \pm 5,341 \mathrm{~mm}$ (nam). Tỉ lệ chiều cao tầng mặt sau/chiêuu cao tâng mặt trước (PFH/AFH) $=0,651 \pm$

${ }^{1}$ Trường Đại học Y Hà Nội

2Bệnh viện Răng Hàm Mặt Trung Ương

Chịu trách nhiệm chính: Đỗ Thị Bình

Email: drbee712@gmail.com

Ngày nhận bài: 22.6.2021

Ngày phản biên khoa học: 18.8 .2021

Ngày duyệt bài: 25.8.2021
0,057 . Chỉ số cắn sâu (ODI) là $61,25 \pm 9,241$, chỉ số loạn sản trước sau (APDI) là 86,97 11,597 , chỉ số kết hợp (CF) là $148,22 \pm 8,642$. Chiêu cao răng hàm lớn thứ nhất hàm trên và hàm dưới lần lượt so với mặt phẳng khẩu cái và mặt phẳng hàm dưới là $\mathrm{d}(\mathrm{U} 6, \mathrm{PP})$

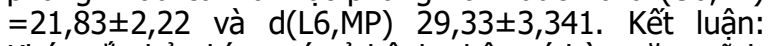
Khớp cắn hở phía trước ở bệnh nhân có hàm răng vĩnh viễn (10-18 tuổi) xuất hiện nhiều ở đối tượng khớp cắn hạng III xương và chiếm phân lớn cắn hở ở mức độ cắn hở mức độ trung bình. Đối tượng này có đặc điểm tăng chiều cao tâng mặt dưới và có kiểu mặt phân ly.

Tư khóa: khớp cắn hở phía trước, cephalometric, người Việt Nam

\section{SUMMARY}

\section{CEPHALOMETRIC CHARACTERISTIC OF} ANTERIOR OPEN BITE IN VIETNAMESE PEOPLE

Anterior open bite (AOB) is a malocclusion that greatly affects function and aesthetics. Besides, longterm stability of $\mathrm{AOB}$ malocclusion is considered challenge for orthodontists. This study aims to describe some morphological characteristics of 36 Vietnamese subjects with anterior open bite between the ages of 10 and 18 years old who had presented the Hanoi Central Odonto-Stomatology Hospital and School of Odonto - Stomatology, Hanoi Medical University. The results of research showed that 
anterior open bite in Vietnamese people is a rare type of malocclusion. It is more common in women, but no statistically significant difference was found between the genders. Most of the subjects had moderate anterior open bite $(-1.39 \pm 0.499 \mathrm{~mm})$. The largest proportion is class III skeletal $(n=15 ; 41.7 \%)$, the lower anterior facial height (LAFH) is $63.41 \pm 6.185 \mathrm{~mm}$ (female) and $68.29 \pm 5,341 \mathrm{~mm}$ (male). The posterior/anterior facial height ratio $(\mathrm{PFH} / \mathrm{AFH})=$ $0.651 \pm 0.057$. The overbite depth indicator (ODI) is $61.25 \pm 9,241$, the antero-posterior dysplasia indicator (APDI) is $86.97 \pm 11,597$, the combined factor (CF) is $148.22 \pm 8.642$. The height of the maxillary and mandibular first molars relative to the palatal plane and mandibular plane, respectively, is $\mathrm{d}(\mathrm{U} 6, \mathrm{PP})=$ $21.83 \pm 2.22$ and $d(L 6, M P) 29.33 \pm 3,341$. Conclusion: Anterior open bite in subjects with permanent teeth (10-18 years old) occurs more frequently in skeletal class III pattern. The majority of subjects had moderate degree of open bite. They showed the characteristics of increasing the anterior facial height and has a hyperdivergent skeletal pattern.

Keywords: anterior open bite, cephalometric, Vietnamese

\section{I. ĐĂT VẤN ĐỀ}

Khớp cắn hở phía trước là tình trang sai khớp cắn, trong đó không có sự phủ các răng phía trước hàm trên và hàm dưới ở tư thế cắn khít trung tâm. Loại khớp cắn này không chỉ ảnh hưởng thẩm mỹ mà còn ảnh hưởng chức năng nhai, phát âm. Đặc biệt, khớp cắn hở phía trước là một trong năm yếu tố chính thuộc khớp cắn được cho là liên quan đến rối loạn khớp thái dương hàm.

X-quang so nghiêng tele từ xa (cephalometrics) vẫn được sử dụng rộng rãi trong thực hành chỉnh nha, chúng đóng vai trò quan trọng trong việc lập kế hoạch và chẩn đoán kế hoạch chỉnh nha kể từ khi được giới thiệu bởi Broadbent giới thiệu vào năm 1931.

Trên thế giới, những nghiên cứu đầu tiên về khớp cắn hở được thực hiện từ khoảng giữa thể kỉ 20. Các nhà khoa học đã đưa ra phân loại, dịch tễ, bệnh sinh, căn nguyên, hình thái, điều trị và sự ổn định sau điêu trị nhưng khớp cắn hở vẫn tỏ ra một loại sai khớp cắn khó kiểm soát và dễ tái phát.

Hiện chưa có nghiên cứu nào về đặc điểm hình thái người Việt Nam có khớp cắn hở được công bố. Xuất phát từ thức trang này, chúng tôi tiến hành nghiên cứu: "Một số đặc điểm hinh thái khớp cănn hở người Việt Nam trên phim so nghiêng tele từ xa (Cephalometrics)" với mục tiêu: Mô tả đặc điểm mô cứng của bệnh nhân có khớp cắn hở trên phim Cephalometrics tại bệnh viên Răng Hàm Mặt Trung Ương và Viện Đào tạo Răng Hàm Mặt.

\section{II. ĐỐI TƯỢNG VÀ PHƯƠNG PHÁP NGHIÊN CỨU}

\section{1. Đối tương}

Tiêu chuẩn lưa chọn: Phim Cephalometrics của bệnh nhân nhỏ hơn 18 tuổi lưu trữ tại Viện Đào tạo Răng Hàm Mặt và Bệnh viện Răng Hàm Mă̆t Trung Ương thỏa mãn các: độ cắn chùm âm, quốc tịch Việt Nam, hàm răng vĩnh viễn và các răng trước có chân răng đang hình thành ít nhất ở giai đoạn 8 theo phân loại Nolla, độ cắn chùm âm, có đủ phim cephalometrics, phim toàn cảnh và bệnh án, phim đảm bảo thấy được cả mô cứng và mô mềm, nút định vị lỗ ống tai ngoài hai bên trùng nhau, xác định rõ được các điểm chuẩn trên phim.

Tiêu chuẩn loại trừ: Bệnh nhân có tiên sử chỉnh hình răng mặt, phẫu thuật chỉnh hình xương, mất răng phía trước, hiện đang có chụp răng, câu răng.

\section{Phương pháp nghiên cứu:}

Thiêt kếnghiên cứr. Nghiên cứu mô tả cắt ngang

cỡ mẫu nghiên cứu: Trước đây chưa có nghiên cứu tỉ lệ bệnh nhân có khớp cắn hở tại Việt Nam, đồng thời tỉ lệ loại khớp cắn này ít gặp, thay đổi từ 1,5-11\% nên chúng tôi lựa chọn tất cả bệnh nhân có đủ tiêu chuẩn. Thực tế, chúng tôi chọn được 36 bệnh nhân.

\section{Biến số nghiên cứu:}

+ Các biến số về đặc trưng của nhóm đối tượng nghiên cứu: tuổi, giới.

+ Các biến số về đăcc điểm hình thái mô cứng trên phim Cephalometrics: các biến số OB, SNA, SNB, ANB, d(U6,PP), d(L6,MP), (GoGn,SN), PFH/AFH, LAFH, Góc Gonion, ODI, APDI, CF.

Kí hiệu và xác định đường thẳng, các góc, chỉ số được sử dụng

OB Độ cắn chùm, đo bằng mm, tính khoảng cách từ rìa cắn răng cửa hàm trên đến hình chiếu của nó trên mặt phẳng đi qua đỉnh múi răng hàm lớn thứ nhất hàm dưới (L6) và rìa cắn răng cửa hàm dưới.

d(U6,PP) Khoảng cách từ đỉnh múi gân của răng hàm lớn thứ nhất hàm trên đến $P P$.

d(L6,MP) Khoảng cách từ đỉnh múi gân của L6 đến MP

PP Đường thẳng qua ANS, PNS

MP Đường thẳng qua Me và điểm thấp nhất của góc xương hàm dưới

(GoGn,SN) Góc giữa GoGn với SN

PFH Chiều cao tầng mặt sau ( $S$ đến điểm thấp nhất của góc hàm dưới)

AFH Chiêu cao tâng mặt trước, (từ $\mathrm{N}$ đến $\mathrm{Me}$ )

LAFH Chiêu cao tâng mặt dưới (từ Me đến hình chiếu của ANS trên N-Me) 
Góc Gonion Góc giữa MP và tiếp tuyến của cành cao xương hàm dưới

ODI Chỉ số cắn sâu ODI (Overbite Depth Indicator), bằng tổng góc giữa hai góc: góc giữa $\mathbf{A B}, \mathbf{M P}$ và $\mathbf{P P}, \mathbf{F H}$. Trong đó góc $(\mathrm{PP}, \mathrm{FH})$ đổi dấu phụ thuộc độ dốc mặt phẳng khẩu cái. Nếu ANS cao hơn PNS thì $(P P, F H)$ âm và ngược lại, Nếu $P P / / F H$, thì ODI=(AB,MP)

APDI Chỉ số loạn sản trước sau (Anteroposterior Dysplasia Indicator), bằng tổng $\mathbf{3}$ góc:

Góc mặt: Góc giữa FH và $\mathbf{N}$-Pog. Góc PP,FH: dấu thay đổi theo độ dốc PP như trên. Góc giữa $\mathbf{A B}$ và $\mathbf{N}-P o g:$ dấu (+) nếu $\mathrm{A}$ ở sau $\mathrm{N}$ Pog và ngược lại

CF Chỉ số kết hợp (Combined factor), bằng tổng APDI và ODI

\section{Hình 1: Minh họ các điểm mốc và các đường thẳng được sử dụng trên giây actetat chuyên dụng \\ Quy trình tiến hành nghiên cứu}

Bước 1: Những bệnh nhân thỏa mãn tiêu chuẩn lựa chọn. Bước 2: Vẽ phim Cephalometrics trên giấy acetate chuyên dụng và đo đạc. Bước 3: Nhập và xử lý số liệu. Bước 4: Tổng hợp số liệu và viết báo cáo.

3. Xử lý số liệu: Các số liệu sẽ được nhập, xử lý bằng phần mềm thống kê SPSS 20.

4. Đạo đức nghiên cứu: Đây là nghiên cứu quan sát trên phim Cephalometric, nguy cơ đối với đối tượng nghiên cứu và tối thiểu hoặc gần như không có. Khách quan trong đánh giá, phân loại, trung thực trong xử lý số liệu. Đảm bảo quyền riêng tư của đối tượng nghiên cứu, thông tin thu thập chỉ phục vụ mục đích nghiên cứu và giúp công tác dự phòng, điêu trị đạt kết quả tốt hơn.

\section{KẾT QUẢ NGHIÊN CỨU}

1. Đặc điểm của đối tượng nghiên cứu. Nghiên cứu được thực hiện trên phim Cephalometrics ở 36 bệnh nhân (tuổi trung bình $14,5 \pm 2,47$, median $=14$ ), trong đó có 22 nữ $(61,1 \%)$ và 14 nam (38,9\%). Tuy nhiên, tỉ lệ xuất hiện ở nam và nữ khác biệt không có ý nghĩa thống kê (Chi-square $=1,778$, tương ứng với $p=0,182$ với độ tin cậy $95 \%$ ).

Bảng 1: Đặc điểm đôî̉ tượng nghiên cứu

\begin{tabular}{|c|c|c|c|}
\hline \multicolumn{2}{|c|}{ Đặc điếm } & Tấn Số (n) & Ti lệ (\%) \\
\hline \multirow{3}{*}{ Tuổi } & $<14$ & 19 & 52,8 \\
\cline { 2 - 4 } & $>14$ & 17 & 47,2 \\
\cline { 2 - 4 } & Tống & 36 & 100 \\
\hline \multirow{3}{*}{ Giới } & Nam & 14 & 38,9 \\
\cline { 2 - 4 } & Nữ & 22 & 61,1 \\
\cline { 2 - 4 } & Tống & $\mathbf{3 6}$ & $\mathbf{1 0 0}$ \\
\hline
\end{tabular}

Nhân xét: Tỉ lệ cắn hở không có sự khác biệt giữa hai nhóm giới tính và nhóm tuổi trên.

2. Đắc điểm mô cứng bệnh nhân khớp cắn hở trên phim sọ nghiểng Tele từ xa Cephalometric.

Bảng 2: Một số chỉ số về mô cứng bệnh nhân khớp cắn hở trên phim Cephalometric

\begin{tabular}{|c|c|c|c|c|c|}
\hline & $\mathbf{N}$ & Giá trị nhỏ nhất & Giá trị lớn nhất & Trung bình & Độ lệch chuấn \\
\hline OB & 36 & -5 & -1 & -2.17 & 1.207 \\
\hline SNA & 36 & 74 & 92 & 82.28 & 4.096 \\
\hline SNB & 36 & 70 & 94 & 81.39 & 5.602 \\
\hline ANB & 36 & -8 & 9 & .89 & 5.013 \\
\hline U6PP & 36 & 18 & 26 & 21.83 & 2.223 \\
\hline L6MP & 36 & 23 & 37 & 29.33 & 3.431 \\
\hline (GoGn,SN) & 36 & 24 & 48 & 37.39 & 5.939 \\
\hline LAFH & 36 & 53 & 77 & 65.31 & 6.274 \\
\hline PFH/AFH & 36 & .48 & .77 & .6511 & .05687 \\
\hline Góc Go & 36 & 109 & 138 & 127.83 & 6.544 \\
\hline ODI & 36 & 43 & 76 & 61.25 & 9.241 \\
\hline APDI & 36 & 58 & 107 & 86.97 & 11.597 \\
\hline CF & 36 & 117 & 161 & 148.22 & 8.642 \\
\hline
\end{tabular}

Bảng 3: Ti lệ phân loại tương quan vị trí giữa xương hàm trên và xương hàm dưới theo $A N B$

\begin{tabular}{|c|c|c|c|c|c|c|}
\hline \multirow{2}{*}{ ANB (độ) } & \multicolumn{2}{|c|}{ Nam } & \multicolumn{2}{c|}{ Nữ } & \multicolumn{2}{c|}{ Tống } \\
\cline { 2 - 7 } & Tần số & Tỉ lệ (\%) & Tần số & Tîe (\%) & Tần số (n) & Tî lệ (\%) \\
\hline$<\mathbf{0}$ (Class III) & 5 & 13,9 & 10 & 27,7 & 15 & 41,7 \\
\hline
\end{tabular}


VIETNAM MEDICAL JOURNAL N02 - SEPTEMBER - 2021

\begin{tabular}{|c|c|c|c|c|c|c|}
\hline 0-4 (Class I) & 5 & 13,9 & 6 & 16,7 & 11 & 30,6 \\
\hline$>$ 4 (Class II) & 4 & 11,1 & 6 & 16,7 & 10 & 27,8 \\
\hline Tống & 14 & 38,9 & 22 & 61,1 & 36 & 100 \\
\hline
\end{tabular}

Nhận xét: Trong 36 bệnh nhân có: 15 người Class III, 11 người Class I, 10 người Class III, sử dụng test Chi-square cho kết quả bằng 0,088 tương ứng $p=0,957$ khi so sánh với tỉ lệ 4:3:3, như vậy không có sự khác biệt phân bố 3 loại class với tỉ lệ trên. Điều này cho thấy tỉ lệ xướng class III hay gặp nhất trên bệnh nhân có khớp cắn hở.

Bảng 4: Phân loại mức độ cắn hở theo giới tính

\begin{tabular}{|c|c|c|c|c|c|c|c|}
\hline \multirow{2}{*}{ OB } & \multicolumn{2}{|c|}{ Trung bình $(\mathrm{OB} \geq-2)$} & \multicolumn{2}{|c|}{ 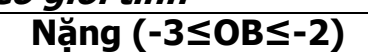 } & \multicolumn{2}{|c|}{ Rất nặng (OB $\leq-4)$} & \multirow{2}{*}{$\begin{array}{l}\text { Tổng } \\
(\%)\end{array}$} \\
\hline & T'ân suất & î lệ (\%) & Tân suất & Tỉ lệ (\%) & Tân suất & Tí lệ(\%) & \\
\hline TB \pm SD $(\mathrm{mm})$ & $-1,39$ & 499 & $-3,27$ & \pm 467 & $-5,00=$ &, 000 & \\
\hline Nam & 9 & 25,0 & 3 & 8,3 & 2 & 5,6 & 38,9 \\
\hline $\mathbf{N}$ & 14 & 38,9 & 8 & 22,2 & 0 & 0 & 61,1 \\
\hline Tống & 23 & 63,9 & 11 & 30,5 & 2 & 5,6 & 100 \\
\hline
\end{tabular}

Nhận xét: Đa số bệnh nhân cắn hở mức độ trung bình. Tỉ lệ nữ cắn hở mức độ trung bình chiếm tỉ lệ nhiều nhất ( $n=14$, tương đương 38,9\%).

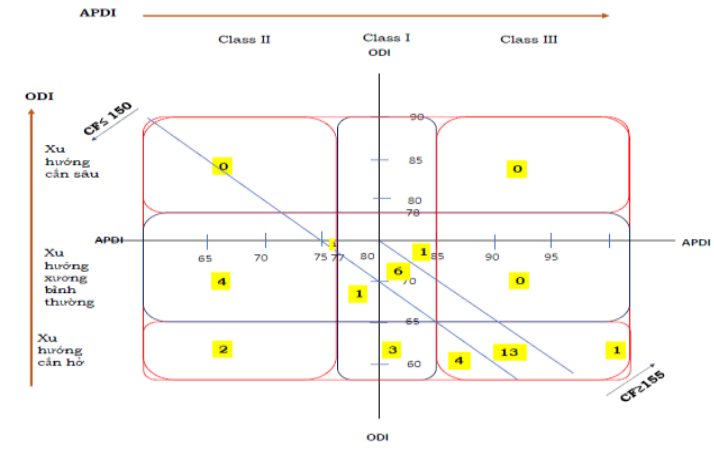

Hình 2: Sơ đồ phân bố các đôí tượng theo $O D I, A P D I, C F$

Nhân xét: Không có bệnh nhân nào có ODI $>78$. Phần lớn thuộc nhóm ODI $\leq 65$ và $A P D I ~ \geq 85$.

Trong 2 bệnh nhân thuộc nhóm CF>155, một bệnh nhân có ODI=54, APDI=107 (Class III, góc cao) và một bệnh nhân có $\mathrm{ODI}=73$ và $A P D I=83$ (Class I, góc thấp).

\section{BÀN LUẬN}

Khớp cắn hở phía trước là một vấn đề khó tiên lượng trong điều trị chỉnh hình răng mặt do nguy cơ tái phát cao, ngay cả khi chỉnh nha và phẫu thuật chỉnh hình xương ${ }^{1}$. Trong nghiên cứu này của chúng tôi cho thấy tỉ lệ trẻ nữ tham gia nghiên cứu cao hơn so với trẻ nam (tuy nhiên sự khác biệt không có ý nghĩa thống kê, có thể giải thích do mẫu nhỏ). Vì không tìm thấy sự khác biệt có ý nghĩa thống kê về giá trị các biến giữa hai nhóm giới tính nên nam và nữ được gộp lại để phân tích.

Chiêu trước sau: Sai khớp cắn hạng III xương chiếm tỉ lệ cao $(n=15 ; 41,7 \%)$, khác biệt có ý nghĩa thống kê so với hai nhóm sai khớp cắn còn lại. Điều này có thể do kiểu mă̆t lõm thường gặp ở hạng III xương gây ảnh hưởng tâm lý cho trẻ và bố mẹ nhiều hơn so với kiểu mặt lồi hoặc phẳng nên trẻ được đi khám nhiều hơn.

Khi xét mối liên hệ giữa mức độ cắn hở với các loại hình sai lệch về xương class I, II, III (phân loại theo ANB) chưa cho thấy mối liên hệ, có thể do cõ̃ mẫu nghiên cứu của chúng tôi chưa đủ lớn để đánh giá tốt.

Chiêuu trên dưới: Phần lớn trẻ cắn hở mức độ trung bình (23 đối tượng), trong đó có 14 nữ. Điều này có thể giải thích do trẻ nữ quan tâm ngoại hình nhiều hơn và ở mức độ chi tiết hơn so với trẻ nam. Và có thể đối tượng cắn hở nặng được tiên lượng phẫu thuật quay lại điều trị khi hêt tăng trưởng ( $\geq 18$ tuổi)

Góc giữa mă̆t phẳng khẩu cái và mặt phẳng Frankfort: 17 đổi tượng có $(\mathrm{FH}, \mathrm{PP}) \leq 0$, chúng chì ra xu hướng xoay ra trước và lên trên của xương hàm trên. Hiện tượng này cũng được ghi lại trong các nghiên cứu trên đối tượng người da trắng².

Góc mặt phẳng hàm dưới (GoGn, SN) tăng có ý nghĩa thống kê so với chỉ số bình thường của người Việt Nam $(29,6 \pm 4,3)$ với $p=0,000$. Phát hiện này phù hợp với các nghiên cứu trước của Sassouni và Nanda?2.

Chiều cao tầng mặt dưới (LAFH) của đối tượng nghiên cứu là $63,41 \pm 6,185 \mathrm{~mm}$ (nữ) và $68,29 \pm 5,341 \mathrm{~mm}$ (nam) cao hơn có ý nghĩa thống kê với kết quả trong nghiên cứu của Nguyễn Thị Trang ${ }^{3}$ và cộng sự trên 168 đối tượng 18-25 tuổi có khớp cắn hạng I và xương hạng I, cho kết quả là $61,04 \pm 4,04 \mathrm{~mm}$ (nữ) và $65,78 \pm 4,80 \mathrm{~mm}$ (nam), và nghiên cứu trên người miền $\mathrm{Nam}^{4}(\mathrm{p}=0,000)$ (năm 2021). Điều này phù hợp với kiểu hình tăng chiều cao tầng mặt dưới trên đối tượng có khớp cắn hở.

$\mathrm{PFH} / \mathrm{AFH}$ trung bình cho kết quả $65,11 \pm 5,687$, chỉ số này thấp hơn có ý nghĩa 
thống kê khi so sánh với chỉ số bình thường của người miền Nam Việt Nam $(68,87 \pm 3,98)$ với $p=0,003$ cho thấy kiểu mặt tăng phân ly ở đối tượng nghiên cứu.

Trong nghiên cứu của $\mathrm{Kim}^{5}$, giá trị ODI và APDI trung bình được đánh giá ở những bệnh nhân từ 7 đến 14 tuổi với độ tuổi trung bình 10,67 tuổi. Người ta đã đưa ra những báo cáo rằng những thay đổi về tăng trưởng xương sọ xảy ra ở độ tuối từ 13 đến 17 tuổi ảnh hưởng đến hàm trên ở mức độ ít. Các nghiên cứu cũng chỉ ra rằng những thay đổi nhỏ về phía trước và theo chiều dọc ở hình thái sọ có thể tiếp tục trong suốt quá trình trưởng thành. Do đó, người ta giả thuyết rằng $\mathrm{ODI}$, APDI trung bình có sự khác biệt đáng kể giữa các bệnh nhân dưới 7 tuổi, từ 7 đến 14 tuổi và trên 14 tuổi (cuối tuổi thanh thiếu niên và người lớn). Cần các nghiên cứu sâu hơn để kiểm tra giả thuyết này.

Trong nghiên cứu của chúng tôi, không có đối tượng nào có chỉ số cắn sâu $\mathrm{ODI}$ cao trên 78 , và có $23 / 36$ bệnh nhân có $O D I \leq 65$. Kết quả này phù hợp với các mốc phân loại trong nghiên cứu của Kim và cộng sự ${ }^{5}$, trong nghiên cứu Kim cho thấy sai khớp cắn hạng III có tần suất liên quan cắn hở cao hơn, ở nghiên cứu chúng tôi tìm thây 18 đối tượng (tỉ lệ cao nhất $50 \%$ ) có ODI $\leq 65$ và APDI $\geq 85$ (cắn hở hạng III). Trong 18 đối tượng này, có 17 đối tượng có giá trị $C F<155$ được phân loại vào nhóm cắn hở hạng III xương góc cao. Đối tượng này chiếm tỉ lệ lớn, đồng thời họ có xu hướng phát triển theo chiều đứng và chủ yếu do quá phát xương hàm dưới (xét trong nhóm này $\mathrm{SNA}=81,78 \pm 4,697, \mathrm{SNB}=85,22 \pm$ $4,333)$, điêu này có lẽ trở thành thách thức lớn cho chỉnh hình răng mặt và có nguy cơ tái phát cao.

Khi so sánh kết quả thu được từ đối tượng nghiên cứu với các chỉ số trên 23 đối tượng cắn hở phía trước người Nhật Bản ${ }^{6}(\mathrm{ODI}=69,1 \pm 8,4$; $A P D I=79,3 \pm 7)$ và 18 đối tượng cắn hở người châu Âu (ODI=66,2 $2 \pm 9,5 ;$ APDI $=79,8 \pm 8,5)^{6}$ đều cho kết quả khác biệt có ý nghĩa thống kê. Trong nghiên cứu, so sánh giá trị ODI, APDI giữa đối tượng cắn hở người Nhật và châu Âu không có sự khác biệt có ý nghĩa thống kê, trừ chỉ số APDI ơ class II.

Có thể thấy đối tượng nghiên cứu người Việt Nam của chúng tôi có giá trị ODI thấp và APDI cao, tương đương với xu hướng phát triển theo chiếu dọc và khớp cắn hạng III (chiếm tỉ lệ cao nhất), CF $\leq 155$ chiếm phần lớn, cho thây tiên lượng sẽ cần nhổ răng khi điều trị và dễ tái phát (theo Kim, APDI quanh giá trị 80 kết quả điều trị ổn định hơn) ${ }^{7}$. Hạn chế của nghiên cứu là chưa có nhóm chứng người Việt Nam cùng độ tuổi, cần thực hiện thêm các nghiên cứu để làm rõ sự khác biệt với người không có khớp cắn hở.

Đặc điểm về răng: Chiều cao răng hàm so với mặt phẳng khẩu cái $\mathrm{d}(\mathrm{U6}, \mathrm{PP})=21,83 \pm 2,223$ và mặ̆t phẳng hàm dưới $\mathrm{d}(\mathrm{L} 6, \mathrm{MP}) 29,33 \pm 3,341$ cho kết quả khác biệt có ý nghĩa thống kê so với nghiên cứu Brazil ${ }^{8} 80$ trẻ từ 11-13 tuổi, class I xương, răng bình thường, thấy trên đối tượng có 3 tâng mặt bình thường (LAFH/AFH =54-56\%) cho kết quả $d(U 6, P P)$ là $27,66 \pm 1,58$ và $d(L 6, M P)=40,1 \pm 2,49$. Có thể giải thích do người Việt Nam có kích thước xương và răng nhỏ hơn người da trắng và cần thêm các nghiên cứu so sánh với người Việt Nam bình thường để tìm căn nguyên từ răng và̀ xương ổ răng nếu có.

\section{KẾT LUẬN}

Khớp cắn hở răng trước của đối tượng có bộ răng vĩnh viễn chưa đến tuổi trưởng thành đến khám ở Viện Đào tạo Răng Hàm Mặt và Bệnh viện Răng Hàm Mặt Trung Ương Hà Nội là İoại hình sai khớp cắn ít gặp. Trên tổng số 36 bệnh nhân, cho thấy sự phân bố nhiều hơn ở nữ (22/36), tuy nhiên sự khác biệt không có ý nghĩa thống kê giữa hai giới. Phẩn lớn $(n=23)$ đối tượng cắn hở mức độ trung bình ( $\mathrm{OB}$ trung bình là $-1,39 \pm 0,499)$ và chỉ có 2 đối tượng thuộc nhóm cắn hở rất nặng. Chiếm tỉ lệ nhiều nhất là sai hạng III xương $(n=15 ; 41,7 \%)$. Chiêu cao tầng mặt dưới (LAFH) trung bình là $63,41 \pm 6,185 \mathrm{~mm}$ (nứ) và $68,29 \pm 5,341 \mathrm{~mm}$ (nam). Tỉ lệ chiều cao tầng mặt sau/chiều cao tầng mặt trước (PFH/AFH) $=0,651 \pm 0,057$. Chỉ số cắn sâu (ODI) là $61,25 \pm 9,241$, chỉ số loạn sản trước sau (APDI) là $86,97 \pm 11,597$, chỉ số kết hợp (CF) là 148,22 $\pm 8,642$. Chiêuu cao răng hàm lớn thứ nhất hàm trên và hàm dưới lần lượt so với mặt phẳng khẩu cái và mặt phẳng hàm dưới là $\mathrm{d}(\mathrm{U} 6, \mathrm{PP})=21,83 \pm 2,22$ và $\mathrm{d}(\mathrm{L} 6, \mathrm{MP}) 29,33 \pm 3,341$.

Lời cảm ơn. Nhóm nghiên cứu xin bày tỏ lời cảm ơn tới các bệnh nhân đã tham gia nghiên cứu và Viện Đào tạo Răng Hàm Mặt - Trường Đại học Y Hà Nội, Bệnh viện Răng Hàm Mặt Trung Ương Hà Nội đã hỗ trợ để thực hiện nghiên cứu này.

\section{TÀl LIỆ THAM KHẢO}

1. Miller JR. Treatment of a twice-relapsed anterior open bite using temporary anchorage devices, myofunctional therapy, and fixed passive selfligating appliances. American Journal of Orthodontics and Dentofacial Orthopedics. 2020;157(6):832-842.

doi:10.1016/j.ajodo.2019.03.031

2. Sassouni V, Nanda S. Analysis of dentofacial 
vertical proportions. American Journal of Orthodontics. 1964;50(11): 801-823. doi:10.1016/ 0002-9416(64) 90039-9

3. Trang NT, Phương NTT, Dũng TM, Hải HV. Đặc điểm mô cứng trên phim so - mặt nghiêng ở Việt trưởng thành có sai khớp cẳn loai I. Accessed September 9, 2021. http:// hocvienquany.edu.vn/ Tapchi_YDHQS/Portal/Default.aspx?MaAbstract $=52257$

4. Ho TTT, Luong QT. Dental-craniofacial Characteristics of Southern Vietnamese People with Well-balanced Face on Cephalometric Films and Its Comparison with Caucasians and Northern Vietnamese Population. J Int Soc Prev Community Dent. 2021;11(3):316-323. doi:10.4103/ jispcd.JISPCD_13_21

5. Kim YH. Overbite depth indicator with particular reference to anterior open-bite. Am J Orthod.
1974;65(6):586-611. doi:10.1016/0002-9416(74) 90255-3

6. Freudenthaler J, Celar A, Kubota M, Akimoto S, Sato S, Schneider B. Comparison of Japanese and European overbite depth indicator and anteroposterior dysplasia indicator values. Eur J Orthod. 2012;34(1):114-118. doi:10.1093/ejo/cjq177

7. MEAW Multi-loop Edgewise Archwire. Dental Library. Published May 14, 2019. Accessed September 6, 2021. https://dental-library.com/ meaw-multi-loop-edgewise-archwire/

8. Enoki $C$, Telles $C$ de $S$, Matsumoto MAN. Dental-skeletal dimensions in growing individuals with variations in the lower facial height. Braz Dent J. 2004;15:68-74. doi:10.1590/ S010364402004000100013

\title{
ĐÁNH GIÁ SỰ CÂN XỨNG MĂT CỦA BÊ̂NH NHÂN SAI KHỚP CẮN LOẠI III TRÊN PHIM CẮT LỚP VI TÍNH 3D
}

\author{
Dương Chí Hiếu ${ }^{1}$, Nguyễn Khánh Long ${ }^{3}$, Nguyễn Trường Minh ${ }^{1,2}$
}

\section{TÓM TẮT}

Giới thiệu: Mục đích của nghiên cứu này là đánh giá sự cân xứng mặt của bênh nhân sai khớp cắn loại III trên phim cắt lớp vi tính 3D. Phương pháp: Nghiên cứu trên phim cắt lớp vi tính 3 chiều của 20 bệnh nhân có sai khớp cắn loại III xương được chia làm 2 nhóm là nhóm bất cân xứng $(n=13)$ và nhóm cân xứng $(n=7)$ theo độ lệch của điểm Menton (Me) mô mềm đến măt phẳng dọc giữa. Kết quả: Bệnh nhân nhóm bất cẩn xứng có độ lệch của điểm Me trên xương và mô mềm lớn hơn có ý nghĩa so với nhóm cân xứng $(p<0,05)$. Trong nhóm bất cân xứng, chiều dài cành lền và thân xương hàm dưới ở bên không lệch lớn hơn bên lệch cùng phía với Me. Độ chênh lệch giữa chiều dài cành lên và thân xương hàm dưới 2 bên trong nhóm bất cân xứng lớn hơn nhóm cân xứng có ý nghĩa thống kê $(p<0,05)$. Khoảng cách từ điểm Gonion và Jugale bên lệch cùng phía với Me đến các mặt phẳng dọc giữa và mặt phằng đứng ngang lớn hởn bên không lếch. Kết luân: Bất cân xứng măt thể hiện chủ yếu taii các vùng thuộc xương hàm dưới ở cành lên và thẩn xương hàm dưới. Trong nhóm bất cân xứng điểm Gonion và Jugale bên không lệch nằm ở phía trước và gần đường giữa hơn bên lệch cho thấy phức hợp xương hàm trên và hàm dưới có xu hướng xoay về cùng phía bên lệch. Do vậy cần đánh giá chính xác sự cân xứng và bất cân xứng để lên kế hoạch phẫu thuật phù hợp.

${ }^{1}$ Viện Đào Tạo Răng Hàm Mặt, Đại học Y Hà Nội

${ }^{2}$ Bệnh viện Đại học Y Hà Nội

${ }^{3}$ Bênh viên Viêt Nam-Cu Ba

Chịu trách nhiêm chính: Nguyễn Trường Minh

Email: nguyentruongminh@hmu.edu.vn

Ngày nhận bài: 24.6.2021

Ngày phản biên khoa họ: 23.8.2021

Ngày duyệt bài: 30.8.2021
Tư khóa: Bất cân xứng mặt, sai khớp cắn loại III, phim cắt lớp vi tính 3D.

\section{SUMMARY \\ ASSESSMENT OF FACIAL SYMMETRY IN SKELETAL CLASS III ON THREE- DIMENSIONAL COMPUTED TOMOGRAPHY}

Introduction: The purpose of this study was to assess facial symmetry in patients with skeletal Class III. Methods: The patients consisted of 20 adults with skeleton class III, divided into the asymmetry group $(n=13)$ and the symmetry group $(n=7)$ according to the degree of soft-menton deviation. Three-dimensional computed tomography scans were obtained with a spiral computed tomography scanner. Landmarks were designated on the reconstructed 3dimensional surface models. Results: In the asymmetry group, patients showed large shift of menton, mandibular ramus and body lengths were significantly longer on the nondeviated side than on the deviated side $(P<0,05)$. The distance between Gonion and Jugale to Mid-Sagital plane and Coronal Plane were longer on the deviated side than on the nondeviated side. Conclusions: Both ramus and body appeared to contribute to mandibular asymmetry. Maxillomandibular complex had roll and yaw rotations to the menton-deviation. Therefore, it is necessary to carefully evaluate these skeletal units when planning a treatment strategy of facial asymmetry.

Keywords: Facial asymmetry, skeleton class III three-dimensional computed tomography.

\section{I. ĐĂTT VẤN ĐỀ}

Sự bất đối xứng trên khuôn mặt thường thấy ở những bệnh nhân bị sai hình xươnng, đặc biệt là những người bi di dang xương loại III ${ }^{1,2}$. Cằm lệch sang một bên là đặc điểm dễ nhận thấy nhất ở những bệnh nhân có khuôn mặt không 